\title{
Tailoring the Novel Anticoagulants to the Stroke Patient - One Size Does Not Fit All Novel Anticoagulants in Stroke
}

\author{
Adam Lee $^{1,2}$ and Rohan Rajaratnam ${ }^{1-4^{*}}$ \\ ${ }^{1}$ Liverpool Hospital, Sydney, Australia \\ ${ }^{2}$ Campbelltown Hospital, Sydney, Australia \\ ${ }^{3}$ The University of Western Sydney, Sydney, Australia \\ ${ }^{4}$ The University of New South Wales, Sydney, Australia
}

*Corresponding author: Rohan Rajaratnam, Department of Cardiology, Liverpool Hospital, Sydney, NSW, Australia, Tel: + 612 8738 3000; Email: rohanrr@bigpond.com.au

Received date: Oct 1, 2014, Accepted date: Nov 07, 2014, Published date: Nov 13, 2014

Copyright: ( 2014 Lee A, et al. This is an open-access article distributed under the terms of the Creative Commons Attribution License, which permits unrestricted use, distribution, and reproduction in any medium, provided the original author and source are credited.

\begin{abstract}
Warfarin has been the mainstay of anticoagulation therapy for stroke prophylaxis in patients with non-valvular AF for past decades. Recent times have seen the release of four alternative novel anticoagulants that overcome many of the limitations that plagued patients on warfarin in the past. These agents have gained rapid acceptance and are now considered first line therapies for this indication in international guidelines. The approval of dabigatran, rivaroxaban and apixaban by US and European medication authorities has resulted in widespread uptake of these agents.

In this review, we seek to examine the major trials pertaining to these agents with particular attention to patients that have already suffered a stroke (secondary prevention). Issues relevant to stroke physicians including thrombolysis in patients on these agents, timing of initiation of these agents after an acute stroke, reversibility in the setting of haemorrhage and alternative agents will be addressed. Finally, with an expanding choice of available agents, we offer some pragmatic advice regarding tailoring therapy to an individual patient.
\end{abstract}

Keywords: Anticoagulation; Dabigatran; Rivaroxaban; Apixaban; Edoxaban; Warfarin; Stroke

\section{Introduction}

Stroke is an often devastating syndrome involving neurological dysfunction due to impaired perfusion to areas of the brain. Approximately $85 \%$ of these are ischemic in nature whilst the remainder are due to haemorrhage [1]. Whilst many of these ischaemic events are due to in situ thrombosis of cerebral arteries or carotid and vertebral disease, many are due to cardioembolic phenomenon, the majority of which are in the setting of atrial fibrillation (AF). AF predisposes to left atrial stasis and consequential thrombus formation, particularly within the left atrial appendage, which can then dislodge and embolise to the cerebral circulation or other systemic organs. One study [2] showed that $24.6 \%$ of patients had AF detected on their index admission for an ischemic stroke. This prevalence increased with age with up to $44.7 \%$ of patients aged above 90 years old having AF detected on admission for an ischemic stroke.

A stroke that occurs in the setting of AF results in a worse prognosis and more severe neurological debility than strokes outside of this setting [3]. AF is the most common cardiac arrhythmia with increasing prevalence with age. One study [4] estimated the worldwide prevalence of AF to be 33.5 million people in 2010; the prevalence is expected to increase in the coming decades due to the growth in the elderly population. Whilst AF can result in symptoms due to its cardiovascular and haemodynamic sequelae, its significant long term morbidity and mortality is due to this heightened risk of cardioembolic stroke; as such thromboprophylaxis is recommended to mitigate this risk.

Recent trials have shown that patients that were deemed to have cryptogenic strokes after standard investigations, were in fact found to have a high rate of atrial fibrillation if followed up with long term cardiac monitoring with either an implantable cardiac monitor (ICM) or external event monitor [5,6]. 30\% of patients that were followed up with an ICM were found to have suffered atrial fibrillation at 3 years compared to only $3 \%$ of patients who were followed up clinically. With the recent release of a smaller ICM [7] that can be inserted by the bedside, the utility of these devices in these patients is likely to increase leading to significantly greater rates of AF detection and consequential use of anticoagulation in these patients.

Warfarin is highly efficacious; it reduces the risk of ischaemic stroke in the setting of AF by $62 \%$ [8], however it is a drug not without its drawbacks. Warfarin has significant interaction with medications and food. There is significant dose variability between patients and a limited therapeutic window requiring frequent monitoring of coagulation parameters. Warfarin has a slow on and offset requiring concomitant therapy with heparin or enoxaparin during initiation or cessation of the drug. These factors have lead to the under prescription of this medication in up to $65 \%$ of eligible patients [9].

Currently, there are four novel anticoagulation agents (NOACS) with proven efficacy for stroke prophylaxis in patients with nonvalvular AF: this includes the direct thrombin inhibitor, dabigatran, and the Factor-Xa inhibitors, rivaroxaban, apixaban and edoxaban. All four agents have been tested against warfarin in a population of 
patients with non-valvular AF in large, Phase III, multi-centre, randomised controlled trials. These medications overcome many of the limitations of warfarin; they involve fixed dosing regimens for most patients, have few significant interactions with medications or food and do not require regular monitoring of coagulation parameters. Edoxaban is still awaiting regulatory approval in the United States of America (USA) [10] and Europe [11] for this indication, whilst dabigatran, rivaroxaban and apixaban have approval from the Federal Drug Administration (FDA) [12-14] and European Medicines Agency (EMA) [15-17] respectively.

\section{Overview of the Novel Anticoagulants (NOACs)}

\section{Dabigatran}

Since the withdrawal of ximelagatran, dabigatran remains the only oral direct thrombin inhibitor available for the prevention of stroke in patients with non-valvular AF. The RE-LY trial [18], was a partially open-label, multicentre, randomised, non-inferiority trial of 18,113 patients testing two doses of dabigatran (110 mg twice daily [BD] and $150 \mathrm{mg} \mathrm{BD}$ ) against dose-adjusted warfarin in patients with nonvalvular AF. There was an equal spread of patients across $\mathrm{CHADS}_{2}$ scores and approximately $20 \%$ of patients had suffered a prior stroke or TIA. The primary outcome was a composite of stroke (both ischaemic and haemorrhagic) and systemic embolism. Both doses were found to be non-inferior to warfarin ( $p<0.001$ for noninferiority) whilst the higher dose was also found to be superior with a $34 \%$ relative reduction in stroke or systemic embolic events (hazard ratio [HR] 0.66 [0.53 - 0.82], $\mathrm{p}<0.001$ for superiority). Notably, the higher dose of dabigatran is the only currently available therapy that appears to be more effective than warfarin in preventing ischaemic strokes with a relative risk reduction of $24 \%$ (HR 0.76 [0.60-0.98], $\mathrm{p}=$ $0.03)$.There was a trend towards improved mortality with the higher dose of dabigatran (HR 0.88 [0.77 - 1.00], $\mathrm{p}=0.051]$. Both doses were associated with lower rates of haemorrhagic stroke compared to warfarin. Patients on the lower dose had 69\% less haemorrhagic strokes (HR 0.31 [0.17 - 0.56], p < 0.001) whilst those on the higher dose had 74\% less compared to warfarin (HR 0.26 [0.14 - 0.49], p < $0.001)$.

The lower dose of dabigatran was somewhat safer than warfarin with $20 \%$ less major bleeding episodes (HR 0.80 [0.69 - 0.93], $\mathrm{p}=$ 0.003] whilst the higher dose did not show a statistical difference in rates of major bleeding compared to warfarin (HR 0.93 [0.81 - 1.07], p $=0.31]$. Whilst in the original RE-LY trial, rates of intracranial and extracranial bleeding were not statistically different from warfarin with either dose of dabigatran, a subsequent analysis [19] demonstrated an age interaction; in elderly patients (age $\geq 75$ years), rates of extracranial bleeding were $20 \%$ and $39 \%$ higher in patients on the lower and higher doses of dabigatran respectively (110 mg BD: HR 1.20 [0.97 - 1.48], $\mathrm{p}$ for interaction $=0.001,150 \mathrm{mg}$ BD: HR $1.39[1.13$ $-1.70]$, $\mathrm{p}$ for interaction $<0.001$ ). No such interaction was seen with regards to intracranial bleeding. Although approved in patients with chronic renal impairment down to a creatinine clearance $(\mathrm{CrCl})$ of 30 $\mathrm{mL} / \mathrm{min}$ by Cockgroft Gault, a sub-analysis of RE-LY [20] demonstrated an interaction by degree of renal dysfunction, whereby the reduction in major bleeding compared to warfarin was mainly evident in those with a $\mathrm{CrCl}$ of $\geq 80 \mathrm{~mL} / \mathrm{min}(110 \mathrm{mg}$ : HR $0.41[0.20-$ 0.62 ], $\mathrm{p}=0.0012,150 \mathrm{mg}$ BD: HR 0.59 [0.41 - 0.84], $\mathrm{p}=0.005)$.

Although major bleeding was not increased in patients on the higher dose of dabigatran, bleeding specifically from the gastrointestinal tract did occur $50 \%$ more frequently in patients on this dose of dabigatran compared to those on warfarin (HR 1.50 [1.19-1.89], $\mathrm{p}<0.001]$ an effect that may be related to the direct effect of dabigatran on gastrointestinal mucosa. Warfarin may escape this localised phenomenon due to its requirement for systemic activation with vitamin-K dependent factors in the systemic circulation. Additionally, dyspepsia occurred significantly more often in patients on dabigatran (approximately $11.2-11.8 \%$ ) compared to those on warfarin $(5.8 \%)[p<0.001]$ resulting in a higher rate of drug discontinuation in patients on dabigatran compared to warfarin $(21 \%$ vs $17 \%, \mathrm{p}<0.001)$.

The original RE-LY trial hinted at the suggestion of higher rates of myocardial infarction (MI) which appeared to reach statistical significance in patients on the higher dose of dabigatran compared to warfarin (HR1.38 [1.00 - 1.91], $\mathrm{p}=0.048)$ although overall event rates were low with only 89 out of 6076 (1.5\%) of patients suffering an MI in this group compared to $1.0 \%$ in the warfarin group. A subsequent meta-analysis of all clinical trials of dabigatran compared to alternative anticoagulants including warfarin, heparin and low-molecular weight heparin (LMWH) appeared to support this finding [21]. Nonetheless, a re-evaluation of the RE-LY trial which included events missed in the original trial showed that on re-analysis, the increase in MI with dabigatran was not statistically significant [22].

Whilst RE-LY demonstrated significant efficacy and safety benefits of both doses of dabigatran over warfarin, this benefit was most notable in those patients from centres where control of the internationalised normalised ratio (INR) was poor in patients on warfarin. A sub-analysis of RE-LY which examined outcomes by time in therapeutic range (TTR) [23] showed that the reduction in major bleeding in patients on high dose dabigatran was confined to those from centres where TTR was $<57.1 \%$ (the lowest quartile) ( $p=0.03$ for interaction).

\section{Rivaroxaban}

Rivaroxaban was the first of the class of oral Factor-Xa inhibitors to reach the market for prevention of stroke in patients with non-valvular AF.The ROCKET AF trial [24] was a multi-centre, randomised controlled trial that tested rivaroxaban against warfarin therapy in 14264 patients of this population. Unlike RE-LY, it was truly double blind with use of double dummy medications. The study utilised a single dosing regimen of $20 \mathrm{mg}$ once daily of rivaroxaban, which was reduced to $15 \mathrm{mg}$ daily in patients with a creatinine clearance of $30-$ $49 \mathrm{~mL} / \mathrm{min}$. The population of ROCKET AF was higher risk than that of RE-LY with the majority of patients having a CHADS2 score of at least three. $55 \%$ of the patients had already suffered a stroke, systemic embolism or TIA. Rivaroxaban was found to be non-inferior to warfarin in regards to the primary outcome of stroke or systemic embolism (HR 0.88 [0.75 - 1.03], p < 0.001 for non-inferiority).

There was no statistical differences in overall rates of clinically relevant bleeding between the two groups (HR 1.03 [0.96-1.11], p = 0.44 ). Like with dabigatran, however, there was a higher rate of major gastrointestinal bleeding in the rivaroxaban group $(3.15 \%$ vs $2.16 \%$, p $<0.05)$. There were also more incidences of epistaxis $(10.14 \%$ vs $8.55 \%, \mathrm{p}<0.01)$ and haematuria $(4.16 \%$ vs $3.40 \%, \mathrm{p}<0.05)$ in patients on rivaroxaban [25]. However, consistent with the other direct acting anticoagulants, there was a $33 \%$ reduction in the rates of intracranial haemorrhage with rivaroxaban (HR 0.67 [0.47 - 0.93], $\mathrm{p}=0.02$ ). 
The ROCKET AF trial gave insights and validation into the short acting nature of these new direct acting agents [26]. Patients allocated to rivaroxaban during this trial were recommended to transition to warfarin at the end of the study. As expected, the median time to achieving a therapeutic INR was much higher in those who were on rivaroxaban (13 days vs 3 days) compared to those already on warfarin. The use of unfractionated heparin or LMWH as bridging therapy until the INR was therapeutic was low ( $<2 \%$ in both groups). Those patients on rivaroxaban had a 3.72 fold increase in rates of stroke or systemic embolism during this period of presumed inadequate anticoagulation compared to those who were already on warfarin (HR 3.72 [1.15 - 9.16], p = 0.004) although absolute rates of these events were still low ( $0.48 \%$ vs $0.14 \%$ respectively). However, patients who transitioned from warfarin to rivaroxaban had similar outcomes to those patients treated with rivaroxaban de novo [27].

All agents are excreted via the renal route to various degrees. This has lead to concerns regarding use of these agents in patients with renal impairment. Reassuringly, a sub analysis of ROCKET AF [28] demonstrated that althoughpatients with moderate renal impairment $(\mathrm{CrCl} 30-49 \mathrm{~mL} / \mathrm{min})$ suffered high rates ofbleeding, when treated with the reduced dose of rivaroxaban $(15 \mathrm{mg})$, this population yielded similar benefits in regards to stroke and systemic embolism as those patients treated with warfarin. Additionally, bleeding rates with rivaroxaban in this population were not higher than that of patients on warfarin.

The J-ROCKET AF trial [29] tested rivaroxaban against warfarin in a Japanese population of 1280 patients with non-valvular AF. Due to pharmacokinetic concerns and more conservative established anticoagulation practices in this population, lower doses of rivaroxaban (15 mg daily) and warfarin (target INR 1.6 - 2.5) were compared. The results were consistent with those of the global ROCKET AF trial with a trend towards less stroke and systemic embolism in those patients treated with rivaroxaban (HR 0.49 [0.24 $1.00], \mathrm{p}=0.05)$.

\section{Apixaban}

Apixaban is the third of NOAC to reach the market and the second of the anti-Factor $\mathrm{Xa}$ agents after rivaroxaban. It was primarily tested in the ARISTOTLE trial [30] which was a multi-centre, randomised, double blinded trial in 18201 patients in which apixaban was tested against warfarin in patients with non-valvular AF. Like ROCKET AF, ARISTOTLE was a true double-blind trial with double-dummy design. A single dosing regimen of $5 \mathrm{mg}$ twice daily was prescribed, which was dose adjusted to $2.5 \mathrm{mg}$ twice daily in patients with at least two of the three criteria: age $\geq 80$ years, body weight $\leq 60 \mathrm{~kg}$, or creatinine level $\geq$ $133 \mu \mathrm{mol} / \mathrm{L}$. The population of patients in this trial were lower risk than that of ROCKET AF with only approximately $30 \%$ of patients having a CHADS2 score of 3 or more. $20 \%$ of patients had suffered a prior stroke or TIA.

Patients on apixaban had a $21 \%$ reduction in rates of stroke or systemic embolism compared to those on warfarin (HR 0.79 [0.66 $0.95], \mathrm{p}=0.01$ ). However, unlike the higher dose of dabigatran, this was not driven by reduced ischaemic strokes (HR 0.92 [0.74 - 1.13], p $=0.42$ ), rather by the $49 \%$ reduction in rates of haemorrhagic stroke (HR 0.51 [0.35 - 0.75), p <0.001). In addition to the efficacy benefit, apixaban was also shown to be safer than warfarin with a $31 \%$ reduction in major bleeding (HR 0.69 [0.60 - 0.80], p < 0.001). Interestingly, patients on apixaban did not have higher rates of gastrointestinal bleeding compared to warfarin (HR 0.89 [0.70 - 1.15], $\mathrm{p}=0.37)$ unlike patients on dabigatran or rivaroxaban in their respective trials. Apixaban was equally well tolerated as warfarin in this study ( $7.6 \%$ vs $8.4 \%$ discontinuations respectively). The efficacy and safety benefits of apixaban over warfarin were maintained regardless of the adequacy of INR; in a sub analysis of the ARISTOTLE trial [31], there was no significant interaction between time in therapeutic range of INR and the primary outcome, major bleeding or death, although numerically the safety benefit of bleeding was attenuated in patients from centres with good INR control. Additionally, patients with renal impairment $(\mathrm{CrCl} \leq 50 \mathrm{~mL} / \mathrm{min})$ not only shared the same efficacy benefit as other patients in ARISTOTLE, the reduction in major bleeding was greatest in this group (HR 0.50 [0.38-0.66], $\mathrm{p}=0.03$ for interaction compared to $\mathrm{CrCl} 50-80$ $\mathrm{mL} / \mathrm{min}$ and $>80 \mathrm{~mL} / \mathrm{min}$ ) [32].

Although the efficacy for aspirin as stroke prophylaxis in atrial fibrillation is limited [33], it continues to be utilised in place of anticoagulation, especially in the elderly and those perceived to be at lower risk of stroke [34]. Apixaban is the only direct oral acting anticoagulant that has been directly compared to aspirin in this population of patients. In the AVERROES trial [35], 5599 patients with non-valvular atrial fibrillation who were deemed unsuitable for warfarin, were randomised to apixaban or aspirin. Like ARISTOTLE, the trial was of a double-blind and double dummy design. The dose of apixaban was identical to that of ARISTOTLE, whilst aspirin was prescribed at a dose of 81 to $324 \mathrm{mg}$ daily with the majority (65\%) being on the lowest dose. The predominant reasons for not offering warfarin in these patients were concerns regarding the ability to have INRs measured, patient refusal or perceived low stroke risk (CHADS2 score of 1 ).

Apixaban demonstrated a 55\% reduction in the primary efficacy outcome of stroke and systemic embolism compared to aspirin therapy (HR 0.45 [0.32 - 0.62], $\mathrm{p}<0.001$ ). This was primarily driven by the $63 \%$ reduction in ischaemic strokes (HR 0.37 [0.25 - 0.55], p < $0.001)$.Impressively, this did not come at the cost of increased major bleeding (HR 1.13 [0.74 - 1.75], $\mathrm{p}=0.57]$. Apixaban was very well tolerated with less serious adverse events in patients on this agent compared to those on aspirin $(22.2 \%$ versus $27.2 \%$ respectively, $\mathrm{p}<$ $0.001)$. A pre-specified analysis of patients who had previously suffered a TIA or stroke (14\% of patients) demonstrated the same efficacy benefit of apixaban over aspirin in this subgroup compared to those who had not previously suffered an event ( $p=0.17$ for interaction) [36].

\section{Edoxaban}

The final NOAC that has been tested in patients with non-valvular AF is edoxaban. It, like rivaroxaban and apixaban, is an oral Factor-Xa inhibitor. The ENGAGE AF-TIMI 48 trial [37] was a multi-centre, randomised, double blind, double dummy trial of 21,205 patients in which edoxaban was compared to warfarin in this population of patients. Similar to RE-LY, two dosing regimens were utilised both incorporating dose adjustments for patients with renal impairment. Patients assigned to the high dose of edoxaban received $60 \mathrm{mg}$ daily whilst those assigned to the lower dose received $30 \mathrm{mg}$ daily. Patients with at least one of three risk factors $(\mathrm{CrCl} 30-50 \mathrm{~mL} / \mathrm{min}$, weight $\leq$ $60 \mathrm{~kg}$ or concomitant use of P-glycoprotein inhibitors or dronedarone) received half the dose in their respective groups (30 mg and $15 \mathrm{mg}$ daily respectively). Patients in this trial were of a higher risk cohort with a minimum CHADS2 score of 2 . The majority of patients 
(approximately 77\%) had a CHADS2 score of 2 or $3.28 \%$ had suffered a prior stroke or TIA.

On a modified intention to treat population in the treatment period, both the high and lower doses of edoxaban were found to be non-inferior to warfarin (HR 0.79 [0.63 - 0.99], $\mathrm{p}<0.001$ for noninferiority and HR 1.07 [0.87 - 1.31], $\mathrm{p}=0.005$ for non-inferiority respectively). Although the higher dose of edoxaban showed a trend towards superiority, this did not reach statistical significance when analysed in an intention to treat population over the overall study period (HR 0.87 [0.73 - 1.04], $\mathrm{p}=0.08$ ). Like, the other direct acting anticoagulants, both doses of edoxaban demonstrated reductions in haemorrhagic stroke compared to warfarin (HR 0.54 [0.38 - 0.77], p < 0.001 and HR 0.33 [0.22 - 0.50], p $<0.001$ respectively). The lower dose of edoxaban, however, was associated with $41 \%$ more ischaemic strokes compared to warfarin (HR 1.41 [1.19 - 1.67], $\mathrm{p}<0.001$ ).

Both doses of edoxaban were associated with less major bleeding with the magnitude of benefit being particularly strong for the lower dose (HR 0.80 [0.71 - 0.91], p < 0.001 and HR 0.47 [0.41 - 0.55], p < 0.001 respectively). The higher dose of edoxaban, like high dose dabigatran and rivaroxaban, was associated with a higher rate of gastrointestinal bleeding (HR 1.23 [1.02 - 1.50], p = 0.03) although, surprisingly, patients on the lower dose regimen demonstrated a $33 \%$ reduction in GI bleeds compared to warfarin (HR 0.67 [0.53 - 0.83], p $<0.001)$. There was a trend towards improved mortality in patients on the higher dose of edoxaban (HR $0.92[0.83-1.01], \mathrm{p}=0.08$ ), whilst those on the lower dose regimen had a $13 \%$ mortality benefit (HR 0.87 $[0.79-0.96], \mathrm{p}=0.006]$ presumably due to its safety profile.

\section{Thrombolysis in Patients on NOACs}

In appropriate patients who present with an ischaemic stroke, administration of intravenous thrombolysis within four and a half hours of symptom onset has been shown to improve outcomes [38,39]. For patients already on warfarin, there is conflicting data as to whether thrombolysis is appropriate if the internationalised normalised ratio (INR) is subtherapeutic on presentation [40,41]. Nonetheless, the American Heart Association/American Stroke Association guidelines suggest such therapy is reasonable if the INR is less than 1.7 [42]. Experience with thrombolysis in patients with NOACs has been limited to case studies which have mainly involved inadvertent administration of thrombolysis to patients who, at the time of presentation, were taking dabigatran unbeknownst to the treating physicians [43-45].

Standard tests of anticoagulation such as the activated partial thromboplastin time (APTT) or prothrombin time (PT)/INR cannot be reliably used to quantify the anticoagulant effect of the NOACs. A normal thrombin time (TT) or Hemoclot thrombin inhibitor assay would suggest minimal anticoagulant activity from dabigatran [46]. For the Factor-Xa inhibitors, specific Factor Xa inhibition assays for each individual drug are likely to be required [47]. The limiting factor for these more specific tests of coagulation is their availability in general hospital laboratories; a crucial factor given the time-dependent nature of thrombolysis for ischaemic stroke.

This limited availability of timely and accurate assessment of anticoagulant effect of the NOACs, will limit the eligibility of patients who present with an ischemic stroke on these agents for thrombolysis. Nonetheless, in certain scenarios it can be considered after careful assessment of relevant factors including the timing and certainty of the last NOAC dose, the patient's renal function, the perceived potential benefit of thrombolysis and, if available, the more specific coagulation assays. Early involvement of the haematology service would be prudent. Endovascular interventions may be considered in patients on NOACs who are ineligible for thrombolysis, though evidence supporting this practice is limited to case studies [48].

\section{Timing of NOACs Post-Stroke}

The NOACs have proven efficacy for the secondary prevention of strokes in patients with AF who have previously suffered an stroke or TIA. Approximately $20 \%$ of patients in RE-LY and ARISTOTLE, $28 \%$ of patients in ENGAGE AF-TIMI 48 and 55\% of patients in ROCKETAF had suffered a previous stroke or TIA. However, patients were excluded if they had suffered an acute stroke within 7 days (ARISTOTLE), 14 days (ROCKET-AF) or 30 days (ENGAGE AFTIMI 48 and RE-LY).

The superior efficacy of anticoagulation with warfarin or a NOAC over aspirin needs to be balanced against the risk of precipitating a haemorrhagic transformation of the stroke lesion if therapy is commenced too early. Current guideslines recommended commencing anticoagulation within 2 weeks of a cardioembolic stroke unless it is particularly severe or large [49]. It would be reasonable to use similar clinical judgement when determining when to switch from aspirin to a NOAC, with the caveat that one must account for the immediate effect of NOACs versus the delayed therapeutic effect of warfarin. Apixaban may prove to be a useful option in this setting, as it was demonstrated in AVERROES to have far greater efficacy than aspirin in preventing ischemic strokes with no significant difference in rates of major bleeding or haemorrhagic stroke.

\section{Reversal of NOACs in the Setting of Bleeding}

A remaining concern of the anticoagulants is the current lack of a reversal agent. Whilst in situations of major of life threatening haemorrhage, the effects of warfarin can be reversed with vitamin $\mathrm{K}$, fresh frozen plaza or prothrombin complex concentrate, the anticoagulant effect of the novel anticoagulants cannot be directly reversed at this time. A number of practical guidelines have been published addressing this issue [50,51]. Generalised haemostatic measures whilst awaiting the anticoagulant effect of NOACS to wear off comprise the current strategy in managing bleeding in these patients. In the event of severe bleeding, therapies such as prothrombin complex concentrates (PCC) or activated Factor VIIa can be considered; one must consider that whilst these therapies are unproven in regards to their haemostatic effect in the presence of NOACs, there is a real risk of a pro-thrombotic effect. For patients on dabigatran (but not the Factor Xa inhibitors), haemodialysis can be considered for uncontrolled bleeding.

Despite the lack of reversal agents, studies have demonstrated that patients that bleed on dabigatran or rivaroxaban do not have worse outcomes compared to those that bleed on warfarin [52,53]. The perceived benefit of warfarin's reversibility may be false reassurance and is unlikely to offset the benefit of the universal reduction in haemorrhagic strokes evident across all NOACs when compared to warfarin. The short half-life of these agents mean the main 'reversal agent' in most cases of bleeding will be time. Nonetheless, direct acting reversal agents are currently undergoing Phase III trials; idarucizumab, a monoclonal antibody is being tested in subjects on dabigatran [54] and andexanet alfa, a recombinant decoy Factor Xa molebule, is being tested in subjects on rivaroxaban and apixaban $[55,56]$. 


\section{Role for Warfarin or Anti-platelet Agents}

Despite the improved efficacy, safety and convenience profiles that the NOACs offer over warfarin, there remain clinical scenarios in which warfarin remains the anticoagulant of choice for stroke prevention in AF. All four agents undergo partial renal excretion to various degrees; as such patients with severe renal impairment $(\mathrm{CrCl}<$ $30 \mathrm{~mL} / \mathrm{hr}$ for dabigatran, rivaroxaban or edoxaban and $\mathrm{CrCl}<25$ $\mathrm{mL} / \mathrm{hr}$ for apixaban) should be offered warfarin as these patients were excluded from the clinical trials.

Patients with 'valvular AF' as defined by severe mitral stenosis or mechanical prosthetic valves should be offered warfarin; higher doses of dabigatran have been compared to warfarin in patients with mechanical cardiac valves in the Phase II RE-ALIGN trial which demonstrated that patients on dabigatran had not only increased thromboembolic events but also more bleeding events than those on warfarin [57]. The pathophysiology of thrombus formation on mechanical valves likely differs to that due to atrial stasis; the selective action of the NOACs may be insufficient for this scenario. Factor Xa inhibitors have not been tested in this setting.

Patients with other concomitant indication for warfarin such as the presence of a left ventricular thrombus, severe aortic arch atheroma or a medically managed patent foramen ovale (PFO) which is thought to be directly responsible for an embolic stroke may be best served by warfarin as there is little data regarding the efficacy of NOACs in these settings. Finally, there are scenarios where the physician or patient may feel more comfortable with warfarin. If compliance is questionable, the ability to monitor INRs and an anticoagulation profile that is more forgiving of a missed dose makes warfarin a reasonable choice. Some patients may prefer warfarin as they feel more comfortable with a "tried and tested" medication.

Aspirin has, at best, shown marginal benefit in preventing ischaemic events in patients with AF [33]. International guidelines are moving away from recommending aspirin [58,59]. Given the AVERROES trial showed vastly superior efficacy of apixaban compared to aspirin in preventing strokes with no significant bleeding penalty, there is little reason to consider aspirin monotherapy even in low risk patients. Additionally, any patient who has already suffered a stroke has a minimum CHADSVASc score of 2 and therefore justifies oral anticoagulation.

The combination regimen of aspirin and clopidogrel were tested in the ACTIVE trials. The ACTIVE A trial [60] showed that adding clopidogrel to aspirin reduced vascular events bya relative risk of $11 \%$ (HR 0.89, [0.81 - 0.98], $\mathrm{p}=0.01$ ) at the expected cost of increased major bleeding (HR 1.57 [1.29 - 1.92], p < 0.001). However the ACTIVE W trial [61] demonstrated that dual antiplatelet therapy with aspirin and clopidogrel was inferior to warfarin in preventing vascular events (HR 1.44 [1.18 - 1.76], $\mathrm{p}=0.0003$ ) with no difference in major bleeding ( $\mathrm{p}=0.53)$ and, in fact, $21 \%$ more total bleeding in the patients on antiplatelet therapy (HR 1.21 [1.03 - 1.35], $\mathrm{p}=0.001$ ). There is, therefore, no role in antiplatelet therapy in patients deemed unsuitable for anticoagulation based on bleeding risk alone.

\section{Individualising the Choice of NOAC to the Patient}

With three agents currently on the market, and the fourth pending approval, physicians must choose which anticoagulant they wish to offer their patients if he or she is deemed appropriate for a NOAC. One must be cautious in making direct comparisons, as these agents have not been directly cross compared in a randomised trial. Nonetheless, the nuances of each individual drug evident within their respective clinical trials make some particularly well or less suited in certain patients. Factors to assist in deciding on individualisation of NOAC therapy in patients with AF are outlined in Tables 1-6. Appropriate dosing regimens for each agent are outlined in Table 7.

\begin{tabular}{|c|c|}
\hline \multicolumn{2}{|c|}{ Dabigatran (high dose) } \\
\hline Strengths & Weaknesses \\
\hline $\begin{array}{c}\text { stroke and systemic embolism than } \\
\text { warfarin }\end{array}$ & $\begin{array}{c}\text { extracranial bleeding than warfarin in } \\
\text { the elderly (age }>75 \text { years) }\end{array}$ \\
\hline ischaemic stroke than warfarin & Gl bleeding than warfarin \\
\hline & $\begin{array}{c}\text { tolerability compared to warfarin } \\
\text { (dyspepsia) }\end{array}$ \\
\hline & Twice daily dosing \\
\hline
\end{tabular}

Table 1: Risk:Benefit Assessment of High Dose Dabigatran

\begin{tabular}{|c|c|}
\hline \multicolumn{2}{|c|}{ Dabigatran (low dose) } \\
\hline Strengths & Weaknesses \\
\hline$\downarrow$ major bleeding than warfarin & $\begin{array}{l}\uparrow \text { extracranial bleeding than warfarin in } \\
\text { the elderly (age }>75 \text { years) }\end{array}$ \\
\hline & $\begin{array}{l}\downarrow \text { tolerability compared to warfarin } \\
\text { (dyspepsia) }\end{array}$ \\
\hline & Twice daily dosing \\
\hline
\end{tabular}

Table 2: Risk:Benefit Assessment of Low Dose Dabigatran

\begin{tabular}{|c|c|}
\hline \multicolumn{2}{|c|}{ Rivaroxaban } \\
\hline Strengths & Weaknesses \\
\hline Once daily dosing & $\begin{array}{c}\text { Gl bleeding, haematuria and } \\
\text { epistaxis than warfarin }\end{array}$ \\
\hline
\end{tabular}

Table 3: Risk:Benefit Assessment of Rivaroxaban

\begin{tabular}{|c|c|}
\hline \multicolumn{2}{|c|}{ Apixaban } \\
\hline Strengths & Weaknesses \\
\hline $\begin{array}{c}\downarrow \text { stroke and systemic embolism than } \\
\text { warfarin and aspirin }\end{array}$ & Twice daily dosing \\
\hline$\downarrow$ major bleeding than warfarin & \\
\hline$\downarrow$ mortality compared to warfarin & \\
\hline Similar bleeding profile to aspirin & \\
\hline$\uparrow$ tolerability compared to aspirin & \\
\hline
\end{tabular}

Table 4: Risk:Benefit Assessment of Apixaban

\begin{tabular}{|c|c|}
\hline \multicolumn{2}{|c|}{ Edoxaban (high dose) } \\
\hline Strengths & Weaknesses \\
\hline$\downarrow$ major bleeding than warfarin & $\uparrow \mathrm{Gl}$ bleeding than warfarin \\
\hline
\end{tabular}


Citation: Lee A, Rajaratnam R (2014) Tailoring the Novel Anticoagulants to the Stroke Patient - One Size Does Not Fit All Novel Anticoagulants in Stroke. J Neurol Neurophysiol 5: 248. doi:10.4172/2155-9562.1000248

Page 6 of 8

\begin{tabular}{|l|l|}
\hline Once daily dosing & \\
\hline
\end{tabular}

Table 5: Risk:Benefit Assessment of High Dose Edoxaban

\begin{tabular}{|l|l|}
\hline \multicolumn{2}{|c|}{ Edoxaban (low dose) } \\
\hline Strengths & Weaknesses \\
\hline
\end{tabular}

\begin{tabular}{|c|c|}
\hline$\downarrow$ major bleeding than warfarin & $\uparrow$ ischaemic strokes than warfarin \\
\hline$\downarrow$ mortality compared to warfarin & \\
\hline Once daily dosing & \\
\hline
\end{tabular}

Table 6: Risk:Benefit Assessment of Low Dose Edoxaban

\begin{tabular}{|c|c|}
\hline \multicolumn{2}{|c|}{ Dosing in Non-Valvular AF } \\
\hline Dabigatran (high dose) & $\begin{array}{l}150 \mathrm{mg} \text { twice daily } \\
\text { Contraindicated if } \mathrm{CrCl}<30 \mathrm{~mL} / \mathrm{hr}\end{array}$ \\
\hline Dabigatran (low dose) & $\begin{array}{l}110 \mathrm{mg} \text { twice daily } \\
\text { Contraindicated if } \mathrm{CrCl}<30 \mathrm{~mL} / \mathrm{hr}\end{array}$ \\
\hline Rivaroxaban & $\begin{array}{l}20 \mathrm{mg} \text { daily if } \mathrm{CrCl} \geq 50 \mathrm{~mL} / \mathrm{hr} \\
15 \mathrm{mg} \text { daily if } \mathrm{CrCl} 30-50 \mathrm{~mL} / \mathrm{hr} \\
\text { Contraindicated if } \mathrm{CrCl}<30 \mathrm{~mL} / \mathrm{hr}\end{array}$ \\
\hline Apixaban & $\begin{array}{l}5 \mathrm{mg} \text { twice daily } \\
2.5 \mathrm{mg} \text { twice daily if at least } 2 \text { of the } 3 \text { : } \\
\text { - Age } \geq 80 \text { years } \\
\text { - Weight }<60 \mathrm{~kg} \\
\text { - Creatinine } \\
\text { Contraindicated if } \mathrm{CrCl}<25 \mathrm{~mL} / \mathrm{hr}\end{array}$ \\
\hline Edoxaban (high dose) & $\begin{array}{l}60 \mathrm{mg} \text { daily } \\
30 \mathrm{mg} \text { daily if at least } 1 \text { of the } 3 \text { : } \\
\mathrm{CrCl} 30-50 \mathrm{~mL} / \mathrm{hr} \\
\text { Weight }<60 \mathrm{~kg} \\
\text { Concomitant } \mathrm{P} \text {-glycoprotein inhibitor or dronedarone use } \\
\text { Contraindicated if } \mathrm{CrCl}<30 \mathrm{~mL} / \mathrm{hr}\end{array}$ \\
\hline Edoxaban (low dose) & $\begin{array}{l}30 \mathrm{mg} \text { daily } \\
15 \mathrm{mg} \text { daily if at least } 1 \text { of the } 3 \text { : } \\
\mathrm{CrCl} 30-50 \mathrm{~mL} / \mathrm{hr} \\
\text { Weight }<60 \mathrm{~kg} \\
\text { Concomitant } \mathrm{P} \text {-glycoprotein inhibitor or dronedarone use } \\
\text { Contraindicated if } \mathrm{CrCl}<30 \mathrm{~mL} / \mathrm{hr}\end{array}$ \\
\hline
\end{tabular}

Table 7: NOAC Dosing Regimens in Patients with Non-Valvular AF

Patients who already have suffered or are at particularly high risk of an ischaemic stroke may best consider the high dose of dabigatran as this is the only regime to result in reduced ischaemic strokes compared to warfarin; conversely low dose dabigatran is probably inadequate in this scenario. Patients that have previously suffered a bleeding event may consider apixaban, either dose of edoxaban or low dose dabigatran (if young) as these regimens have an improved bleeding profile compared to warfarin.

Patients with prior GI bleeding should consider apixaban or low dose edoxaban as these are the only regimens that did not result in higher rates of GI bleeding than warfarin. Patients with a prior history of significant haematuria or epistaxis should consider avoiding rivaroxaban.

Patients at relatively lower risk of stroke but who still require anticoagulation may consider apixaban or low dose edoxaban as these regimens maintain efficacy whilst markedly reducing haemorrhagic risk; this overall balance results in improved mortality compared to warfarin therapy.

Finally, patients may prefer the convenience of once daily dosing, particularly if they have been used to warfarin therapy in the past. Rivaroxaban or one of the edoxaban regimens are reasonable in this circumstance.

\section{Conclusion}

The availability of the NOACs have ushered in a new era of ischaemic stroke prophylaxis in patients with non-valvular AF. International guidelines support the use of these NOACs as first line therapies for stroke prophylaxis in patients with non-valvular AF $[58,59]$. All four agents offer at least equivalent efficacy in preventing 
stroke compared to warfarin, a reduction in risk of haemorrhagic stroke, increased convenience and in some cases improved mortality. Although further research is required to determine the suitability of thrombolysis in patients on these agents, the appropriate timing of initiation of NOACs after an ischaemic stroke and in regards to reversal agents in the setting of catastrophic bleeds, the availability of these agents has dramatically improved the therapeutic options available to stroke physicians and cardiologists.

\section{References}

1. Go AS, Mozaffarian D, Roger VL, Benjamin EJ, Berry JD et al. (2013) Heart disease and stroke statistics 2013 update: a report from the American Heart Association. Circ 2012:e2-241.

2. Marini C, De Santis F, Sacco S, Russo T, Olivieri L, et al. (2005) Contribution of atrial fibrillation to incidence and outcome of ischemic stroke: results from a population-based study.Stroke 36: 1115-1119.

3. Steger C, Pratter A, Martinek-Bregel M, Avanzini M, Valentin A, et al. (2004) Stroke patients with atrial fibrillation have a worse prognosis than patients without: data from the Austrian Stroke registry.Eur Heart J 25: 1734-1740.

4. Chugh SS, Havmoeller R, Narayanan K, Singh D, Rienstra M, et al. (2014) Worldwide epidemiology of atrial fibrillation: a Global Burden of Disease 2010 Study.Circulation 129: 837-847.

5. Giugliano RP, Ruff CT, Braunwald E, Murphy SA, Wiviott SD, et al. (2013) Edoxaban versus warfarin in patients with atrial fibrillation.N Engl J Med 369: 2093-2104.

6. Sanna T, Diener HC, Passman RS, Di Lazzaro V, Bernstein RA, et al. (2014) Cryptogenic stroke and underlying atrial fibrillation.N Engl J Med 370: 2478-2486.

7. Reveal Insertable Cardiac Monitor (ICM).

8. Hart RG, Benavente O, McBride R, Pearce LA (1999) Antithrombotic therapy to prevent stroke in patients with atrial fibrillation: a metaanalysis.Ann Intern Med 131: 492-501.

9. Samsa GP, Matchar DB, Goldstein LB, Bonito AJ, Lux LJ, et al. (2000) Quality of anticoagulation management among patients with atrial fibrillation: results of a review of medical records from 2 communities.Arch Intern Med 160: 967-973.

10. Diichi Sankyo Submits SAVAYSA (edoxaban) Tablets New Drug Application to the U.S. Once-Daily Use for Stroke Risk Reduction in Atrial Fibrillation and for the Treatment and Prevention of Recurrence of Venous Thromboembolism.

11. Daiichi Sankyo Submits Edoxaban Marking Authorization Application to the EMA for Once-Daily Stroke Prevention in Atrial Fibrillation and for the Treatment and Prevention of Recurrence of Venous Thromboembolism.

12. FDA approves Pradaxa to prevent stroke in people with atrial fibrillation.

13. FDA approves Xarelto to prevent stroke in people with common type of abnormal heart rhythm.

14. FDA approves Eliquis to reduce the risk of stroke, blood clots in patients with non-valvular atrial fibrillation.

15. European Medicines Agency Find medicine Pradaxa.

16. European Medicines Agency Find medicine Xarelto.

17. European Medicines Agency Find medicine Eliquis.

18. Connolly SJ, Ezekowitz MD, Yusuf S, Eikelboom J, Oldgren J, et al. (2009) Dabigatran versus warfarin in patients with atrial fibrillation.N Engl J Med 361: 1139-1151.

19. Eikelboom JW, Wallentin L, Connolly SJ, Ezekowitz M, Healey JS et al. (2011) Risk of bleeding with 2 doses of dabigatran compared with warfarin in older and younger patients with atrial fibrillation: an analysis of the randomized evaluation of long-term anticoagulation therapy (RELY) trial. Circulation 123: 2363-2372.

20. Hijazi Z, Hohnloser SH, Oldgren J, Andersson U, Connolly SJ et al. (2014) Efficacy and Safety of Dabigatran Compared With Warfarin in
Relation to Baseline Renal Function in Patients With Atrial Fibrillation: A RE-LY (Randomized Evaluation of Long-term Anticoagulation Therapy) Trial Analysis. Circulation 129: 961-970.

21. Uchino K, Hernandez AV (2012) Dabigatran association with higher risk of acute coronary events: meta-analysis of noninferiority randomized controlled trials.Arch Intern Med 172: 397-402.

22. Hohnloser SH, Oldgren J, Yang S, Wallentin L, Ezekowitz M, et al. (2012) Myocardial ischemic events in patients with atrial fibrillation treated with dabigatran or warfarin in the RE-LY (Randomized Evaluation of LongTerm Anticoagulation Therapy) trial.Circulation 125: 669-676.

23. Wallentin L, Yusuf S, Ezekowitz MD, Alings M, Flather M et al. (2010) Efficacy and safety of dabigatran compared with warfarin at different levels of international normalised ratio control for stroke prevention in atrial fibrillation: an analysis of the RE-LY trial. Lancet 376: 975-983.

24. Patel MR, Mahaffey KW, Garg J, Pan G, Singer DE, et al. (2011) Rivaroxaban versus warfarin in nonvalvular atrial fibrillation.N Engl J Med 365: 883-891.

25. Patel MR, Mahaffey KW, Garg J, Pan G, Singer DE, et al. (2011) Rivaroxaban versus warfarin in nonvalvular atrial fibrillation.N Engl J Med 365: 883-891.

26. Mahaffey KW, Hellkamp AS, Patel MR, Hannan KL, Schwabe K, et al. (2013) End of study transition from study drug to open-label vitamin K antagonist therapy: the ROCKET AF experience.Circ Cardiovasc Qual Outcomes 6: 470-478.

27. Mahaffey KW, Wojdyla D, Hankey GJ, White HD, Nessel CC, et al. (2013) Clinical outcomes with rivaroxaban in patients transitioned from vitamin $\mathrm{K}$ antagonist therapy: a subgroup analysis of a randomized trial.Ann Intern Med 158: 861-868.

28. Fox KA, Piccini JP, Wojdyla D, Becker RC, Halperin JL, et al. (2011) Prevention of stroke and systemic embolism with rivaroxaban compared with warfarin in patients with non-valvular atrial fibrillation and moderate renal impairment.Eur Heart J 32: 2387-2394.

29. Hori M, Matsumoto M, Tanahashi N, Momomura S, Uchiyama S, et al. (2012) Rivaroxaban vs. warfarin in Japanese patients with atrial fibrillation â $€$ “ the J-ROCKET AF study â€“.Circ J 76: 2104-2111.

30. Granger CB, Alexander JH, McMurray JJ, Lopes RD, Hylek EM, et al. (2011) Apixaban versus warfarin in patients with atrial fibrillation.N Engl J Med 365: 981-992.

31. Wallentin L, Lopes RD, Hanna M, Thomas L, Hellkamp A et al. (2013) Efficacy and Safety of Apixaban Compared With Warfarin at Different Levels of Predicted International Normalized Ratio Control for Stroke Prevention in Atrial Fibrillation. Circulation 127: 2166-2176.

32. Hohnloser SH, Hijazi Z, Thomas L, Alexander JH, Amerena J, et al. (2012) Efficacy of apixaban when compared with warfarin in relation to renal function in patients with atrial fibrillation: insights from the ARISTOTLE trial.Eur Heart J 33: 2821-2830.

33. McNamara RL, Tamariz LJ, Segal JB, Bass EB (2003) Management of atrial fibrillation: review of the evidence for the role of pharmacologic therapy, electrical cardioversion, and echocardiography.Ann Intern Med 139: 1018-1033.

34. Bajorek BV, Ren S (2012) Utilisation of antithrombotic therapy for stroke prevention in atrial fibrillation in a Sydney hospital: then and now.Int J Clin Pharm 34: 88-97.

35. Connolly SJ, Eikelboom J, Joyner C, Diener HC, Hart R, et al. (2011) Apixaban in patients with atrial fibrillation.N Engl J Med 364: 806-817.

36. Diener HC, Eikelboom J, Connolly SJ, Joyner CD, Hart RG et al.(2012) Apixaban versus aspirin in patients with atrial fibrillation and previous stroke or transient ischaemic attack: a predefined subgroup analysis from AVERROES, a randomised trial. Lancet Neurol 11: 224-231.

37. Giugliano RP, Ruff CT, Braunwald E, Murphy SA, Wiviott SD, et al. (2013) Edoxaban versus warfarin in patients with atrial fibrillation.N Engl J Med 369: 2093-2104.

38. [No authors listed] (1995) Tissue plasminogen activator for acute ischemic stroke. The National Institute of Neurological Disorders and Stroke rt-PA Stroke Study Group.N Engl J Med 333: 1581-1587. 
Citation: Lee A, Rajaratnam R (2014) Tailoring the Novel Anticoagulants to the Stroke Patient - One Size Does Not Fit All Novel Anticoagulants in Stroke. J Neurol Neurophysiol 5: 248. doi:10.4172/2155-9562.1000248

Page 8 of 8

39. Hacke W, Kaste M, Bluhmki E, Brozman M, Dávalos A, et al. (2008) Thrombolysis with alteplase 3 to 4.5 hours after acute ischemic stroke.N Engl J Med 359: 1317-1329.

40. Ruecker M, Matosevic B, Willeit P, Kirchmayr M, Zangerle A, et al. (2012) Subtherapeutic warfarin therapy entails an increased bleeding risk after stroke thrombolysis.Neurology 79: 31-38.

41. Xian Y, Liang L, Smith EE, Schwamm LH, Reeves MJ et al. Risks of intracranial haemorrhage among patients with acute ischemic stroke receiving warfarin and treated with intravenous tissue plasminogen activator. JAMA 3007: 2600-2608.

42. Jauch EC, Saver JL, Adams HP, Bruno A, Connors JJ et al. (2013) Guidelines for the Early Management of Patients With Acute Ischemic Stroke: A Guideline for Healthcare Professionals From the American Heart Association/American Stroke Association. Stroke 44: 870-947.

43. Lee VH, Conners JJ, Prabhakaran S (2012) Intravenous thrombolysis in a stroke patient taking dabigatran.J Stroke Cerebrovasc Dis 21: 916.

44. Sangha N, El Khoury R, Misra V and Lopez G (2012) Acute ischemic stroke treated with intravenous tissue plasminogen activator in a patient taking dabigatran with radiographic evidence of recanalization. J Stroke Cerebravasc Dis 21: 917.e5-8.

45. Naranjo IC, Portilla-Cuenca JC, Jimenez Caballero PE, Escobar MLC Sevilla RMR (2011) Fatal intracerebral haemorrhage associated with administration of recombinant tissue plasminogen activator in a stroke patient on treatment with dabigatran. Cerebrovasc Dis 32: 614-615.

46. Hapgood G, Butler J, Malan E, Chunilal S and Tran H (2013) The effect of dabigatran on the activated partial thromboplastin time and thrombin time as determined by the Hemoclot thrombin inhibitor assay in patient plasma samples. Thrombosis \& Haemostasis 110: 308-315.

47. Samama MM, Contant G, Spiro TE, Perzborn E, Le Flem L, et al. (2013) Laboratory assessment of rivaroxaban: a review.Thromb J 11: 11.

48. Müller P, Topakian R, Sonnberger M, Nußbaumer K, Windpessl M, et al. (2013) Endovascular thrombectomy for acute ischemic stroke patients anticoagulated with dabigatran.Clin Neurol Neurosurg 115: 2257-2259.

49. Kernan WN, Ovbiagele B, Black HR, Bravata DM, Chimowitz MI et al. (2014) Guidelines for the Prevention of Stroke in Patients With Stroke and Transient Ischemic Attack: A Guideline for Healthcare Professionals From the American Heart Association/American Stroke Association. Stroke 45: 2160-2236
50. Siegal DM1, Crowther MA (2013) Acute management of bleeding in patients on novel oral anticoagulants.Eur Heart J 34: 489-498b.

51. Heidbuchel H, Verhamme P, Alings M, Antz M, Hacke W et al. (2013) EHRA Practical Guide on the use of new oral anticoagulants in patients with non-valvular atrial fibrillation: executive summary. Eur Heart J 34: 2094-2106.

52. Majeed A, Hwang HG, Connolly SJ, Eikelboom JW, Ezekowitz MD, et al. (2013) Management and outcomes of major bleeding during treatment with dabigatran or warfarin.Circulation 128: 2325-2332.

53. Piccini JP, Garg J2, Patel MR2, Lokhnygina Y2, Goodman SG3, et al. (2014) Management of major bleeding events in patients treated with rivaroxaban vs. warfarin: results from the ROCKET AF trial.Eur Heart J 35: $1873-1880$.

54. Reversal of Dabigatran Anticoagulant Effect With Idarucizumab.

55. A Study in Older Subject to Evaluate the Safety and Ability of Andexanet Alfa to Reverse the Anticoagulation Effect of Rivaroxaban.

56. A Study in Older Subjects to Evaluate the Safety and Ability of Andexanet Alfa to Reverse the Anticoagulation Effect of Apixaban.

57. Eikelboom JW, Connolly SJ, Brueckmann M, Granger CB, Kappetein AP, et al. (2013) Dabigatran versus warfarin in patients with mechanical heart valves.N Engl J Med 369: 1206-1214.

58. Camm AJ, Lip GYH, De Caterina R, Savelieva I, Atar D et al. (2012) focused update of the ESC Guidelines for the management of atrial fibrillation: An update of the 2010 ESC Guidelines for the management of atrial fibrillation. Eur Heart J 33: 2719-2747.

59. January CT, Wann LS, Alpert JS, Calkins H, Cleveland Jr JC et al. (2014) AHA/ACC/HRS/Guideline for the Management of Patients With Atrial Fibrillation: Executive Summary. J Am Coll Cardiol.

60. ACTIVE Investigators, Connolly SJ, Pogue J, Hart RG, Hohnloser SH, et al. (2009) Effect of clopidogrel added to aspirin in patients with atrial fibrillation.N Engl J Med 360: 2066-2078.

61. The ACTIVE Writing Group on behalf of the ACTIVE Investigators (2006) Clopidogrel plus aspirin versus oral anticoagulation for atrial fibrillation in the Atrial fibrillation Clopidogrel Trial with Irbesartan for prevention of Vascular Events (ACTIVE W): a randomised controlled trial. Lancet 367: 1903-1912. 